\title{
The Effect of Psychological Contract Violation in Employees' Emotional Labor Strategies-Mediating Model with Regulation
}

\author{
Li mucun ${ }^{1}$, Zhang yuting ${ }^{2}$, Chen yiwen ${ }^{3, *}$ \\ ${ }^{1}$ CAS Key Laboratory of Behavioral Science, Institute of Psychology, Beijing 100101, China \\ ${ }^{2}$ Department of Psychology, University of Chinese Academy of Sciences, Beijing 100049 China.
}

\begin{abstract}
Emotional labor is the process of regulating expressions and emotions to meet organizational goals, including surface performance and deep performance. Based on psychological contract theory and stress theory, this study investigates the effect of psychological contract breach on emotional labor and the mediating role of job insecurity, which is mediated by personality traits, on this effect.
\end{abstract}

\section{Question.}

In 2016, the State Council issued the "Thirteen Fifths" National Strategic Emerging Industries Development Plan, in which the document clearly elaborated the development direction of the new energy industry industry as well as its goals, and the trend of new energy vehicle enterprises building plants was in full swing and sprung up, but in 2017 there was a great impact of "fraudulent subsidies storm", which largely reduced the possibility of speculation in new energy vehicles to obtain high profits, in 2017, due to the reduction of financing channels in the new energy market and the substantial fluctuations in the market, due to financial pressure and not involved in new energy projects have been slowly eliminated, the China Automobile Association published in 2018 to the public Information on the auto industry, in which the national auto production and sales achieved 28.081 million units and 27.809 million units respectively, a decrease of $2.8 \%$ and $4.2 \%$ year-on-year respectively. Externally, corporate fluctuations affect the market economy, and internally, a large number of employees are forced to leave and jump ship voluntarily.

Experiencing layoffs and other organizational changes can cause employees to feel that their psychological contract with their employer is being violated (Probst \& Lawler, 2006).Highly insecure employees, in order to maintain their current jobs and work environment, will adopt emotional labor strategies to conform to the requirements of organizational rules and reduce the likelihood of passive separation (Grandey A., 2000). Surface performance has a negative impact on employees' physical and mental health, leading to emotional numbness, emotional exhaustion and reduced loyalty, while deep performance up to promotes employees' job satisfaction and fulfillment, increasing loyalty. Therefore, how to suppress the surface performance of employees and promote the deep performance becomes one of the challenges faced by managers.

\subsection{Psychological contract breach and job insecurity}

Greenhalgh and Rosenblatt (1984) suggested that "job insecurity is the feeling of powerlessness in a threatening work environment with respect to maintaining the permanence of the desired job." Roskies \& Louis-Guerin (1990) stated, "Job insecurity is an individual's concern about job continuity." The psychological contract gives employees a sense of control or predictability, and any perceived variable that affects this control may lead to job insecurity (Ashford et al., 1991). Psychological contract breach and reduced job insecurity occur simultaneously when employees feel they have less control over their future work. Anticipated organizational change has also been shown to be positively related to perceived job insecurity (e.g., Burke, 1998 ; Ito \& Brotheridge , 2007). Based on the above analysis, the following hypotheses are proposed in this paper:

H1: Psychological contract breach has a positive effect on job insecurity

\subsection{Psychological contract breach and emotional labor}

Emotional labor is the emotional control that individuals exercise in order to exhibit company-demanding behaviors during social interactions (Glomb \& Tews, 2004). According to the mental process of the emotional labor journey, Hochschild (1983) divided it into Surface Acting and Deep Acting. The former is the emotion that 
the individual has inside, and it is a kind of disguise to abandon the expression of emotion that should be reflected, and to reflect the "appropriate" emotion according to the presentation principle required by the company. The latter is where the individual uses control of inner thoughts to turn them into actual emotional experiences that reflect the company's required emotions in the true sense of the word, that is, true emotions.

Psychological contract breach can cause negative emotions in employees, and negative emotional events are positively associated with emotional labor (Wadi Y M., 2000). Gross (1998) argues that when employees feel less psychological contract violation, they are more able to adjust their internal feelings through self-perception assessment. Based on the above analysis, the following hypotheses are proposed in this paper:

H2a: Psychological contract breach has a positive effect on surface performance

H2b: Psychological contract breach has a negative effect on deep performance

\subsection{The mediating role of job insecurity}

Researchers further suggest that job insecurity is a subjective phenomenon, a subjective perception or expectation of a stressful event in which employees' job survival is at risk or threatened, rather than an actual loss of work (Sverke M, Hellgren J, 2002). This paper focuses on Employees' concerns about losing their jobs in the context of industry instability, so the focus is on quantitative job insecurity(Hellgren J., Sverke M., Isaksson K. ,1990)

De Witte's study in a plant that had not undergone organizational change for almost 10 years also showed job insecurity to be an important source of stress (De WH., 1999), and that employees in stressful work situations will adopt emotional labor strategies to self-regulate and conform to organizational rules in order to maintain their current jobs and work environment (Grandey A., 2000):

H3a: Job insecurity has a positive effect on surface performance

H3b: Job insecurity has a positive effect on deep performance

Morris and Feldman (1996) identified the effort, planning, and control required to express organizationally desired emotions in interpersonal interactions, a definition derived from an interactionist approach in which emotions are expressed in, and partially determined by, the social environment. Considering that psychological contract breach precedes job insecurity and job insecurity precedes emotional labor, it is inferred that job insecurity may be a mediating variable between psychological contract breach and emotional labor based on the relationship between the variables proposed by Baron and Kenny (1986). If mediating effects exist, are the effects consistent for different dimensions of emotional labor (surface versus deep performance)? Based on the above analysis, the following hypotheses are proposed in this paper:

H4a: Job insecurity mediates between psychological contract breach and surface performance

H4b: Job insecurity mediates between psychological contract breach and deep performance

\subsection{Moderating effects of the Big Five personality}

Our scholars have a unified view on the way personality is described, pointing out five forms of personality (Big Five) (Goldberg, 1992). These five traits are: (1) neuroticism. (2) Due diligence. (3) Pleasantness. (4) Openness. (5) Outward-looking. Represents the amount and density of interpersonal communication, the need for stimulation, and the ability to feel pleasure (Goldberg, 1992).

The above mediators may be moderated by personality; on the one hand, job insecurity is an individual perception, and even in the same work environment, there may be differences in the perceived security of people with various personality traits (Zhang, Li, Lin \& Chuan, and Zhang, Lin, 2013). Kiffin-Petersen et al. (2011) only confirmed that neuroticism positively affects surface performance and extraversion positively affects deep performance, and the results of studies on extraversion suggest that people who feel more positive emotions are more likely to faking the emotions they want, results on neuroticism suggest that individuals who typically experience negative emotions may need to fake positive emotions to meet role expectations, but James M. and Diefendor (2015) have demonstrated in their research that in addition to openness to experience, all of the Big Five personalities are significantly and uniquely related to at least one emotional labor strategy variable.

Based on the above analysis, the following hypotheses are proposed in this paper:

H5a: Neuroticism regulates the effect of job insecurity on surface performance

H5b: The effect of responsibility to moderate job insecurity on deep performance

H5c: Extroversion moderates the effect of job insecurity on deep performance

H5d: The effect of work insecurity on deep performance as moderated by desirability

H5e: Openness of experience moderates the effect of job insecurity on deep performance

In summary, the hypothetical model of this study is shown in Figure 1 


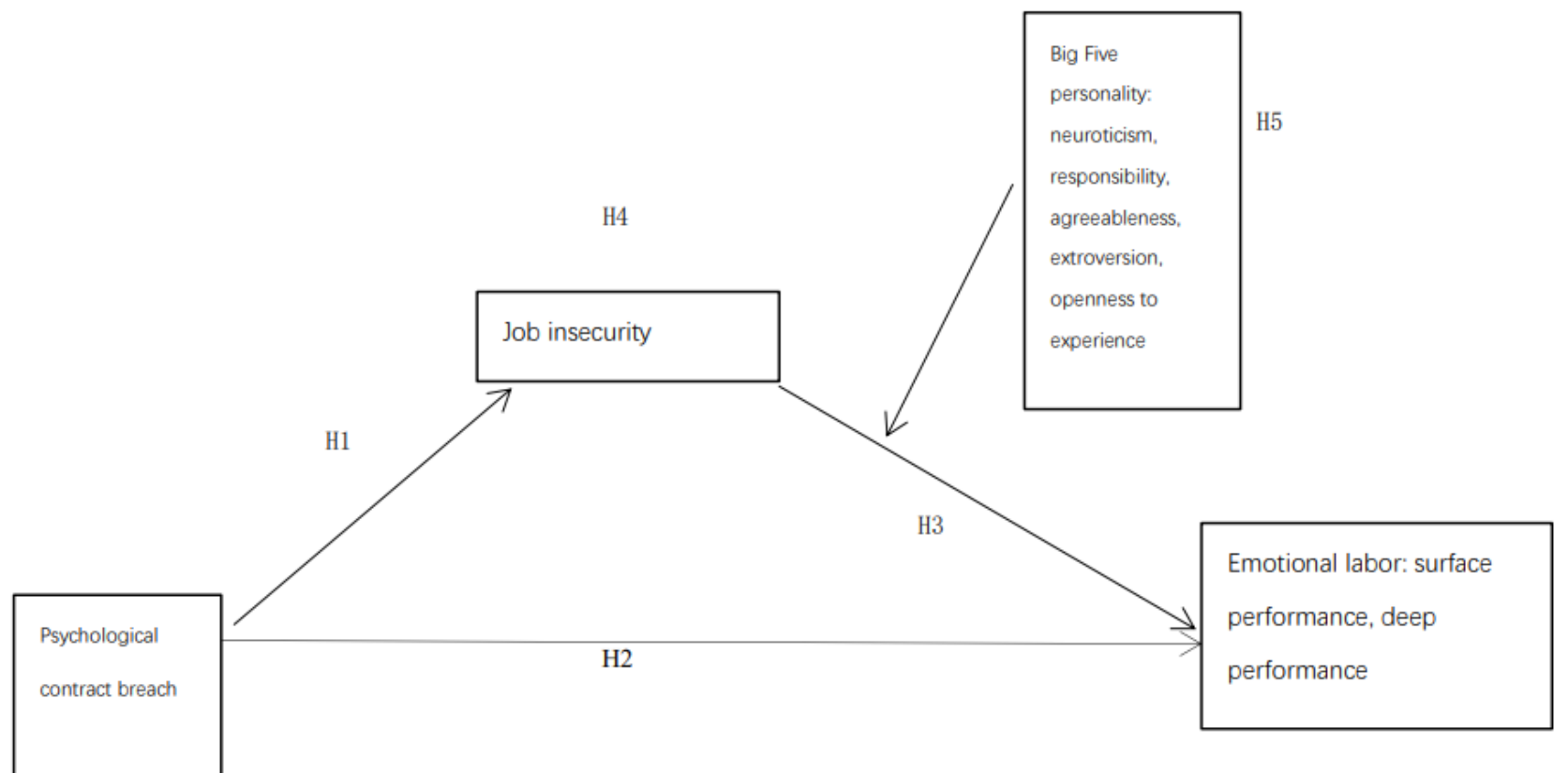

Figure 1: Theoretical model of this study

\section{Research Methodology}

\subsection{Subjects}

In this study, the working employees of new energy manufacturing enterprises were surveyed, and the enterprises were located in 6 provinces of Jiangsu, Zhejiang, Beijing, Sichuan, Chongqing, and Yunnan, and a total of 292 employees participated in this survey, with 280 valid questionnaires, and the effective recovery rate of questionnaires was $95.9 \%$, including 48 female employees (17.14\%) and 232 male employees (82.86\%), and the average age of the subjects was 35 years old $(\mathrm{SD}=0.95$ years old), and the age range was between 30 and 40 years old.

\subsection{Measurement tools.}

\subsubsection{Psychological contract breach.}

Psychological contract violation was measured using the Chinese local scale designed by Zhang Shuang et al. (2012), which refers to Rousseau's (1988, 2000) Psychological Contract Questionnaire and the questionnaire used by Chen Jiazhou and Ling Wen spokesperson (2003) in China, including 16 items. The value of Cronbach's $\alpha$ coefficient in this survey is 0.88 .

\subsubsection{Job insecurity.}

Job insecurity was measured using De Cuyper et al.'s (2014) 4-item scale, in which employees rated their current state of experienced insecurity, with the 4 items measuring primarily quantitative insecurity, which was measured on a 5-point Likert scale.The value of
Cronbach's $\alpha$ coefficient in this survey was 0.721 .

\subsubsection{Emotional labor.}

The questionnaire cited is the Emotional Labor Questionnaire developed by Grandey, which contains 11 items: the surface performance consists of questions 1-5, and the deep performance consists of questions 6-11. The questionnaire is measured on a 5-point Likert scale.The value of Cronbach's $\alpha$ coefficient in this survey is 0.701 .

\subsubsection{Big Five personality.}

The Big Five Personality Inventory is based on the Chinese Big Five Personality Questionnaire Minimal (CBF-PI-15), which is based on the CBF-PI-B (eg. Xia, J., Wu, D., Zhong, X., \& Nie, Xueqing, 2013) and contains 15 items. was measured on a 6-point Likert scale.In this survey, the Cronbach's alpha coefficient value for the total questionnaire was 0.707 , and the Cronbach's alpha coefficients for each subquestionnaire were 0.789 for neuroticism, 0.7 for dutifulness, 0.729 for agreeableness, 0.851 for openness, and 0.742 for extraversion.

\subsubsection{Control variables.}

Because age tends to reflect an individual's general experience of interacting with others, and women perform more emotionally related tasks at work (Hochschild, 1983), the age and gender of the subjects were included as control variables in this study. Second, considering that employees' years of experience and job position may affect their perceptions of their jobs, this study included years of experience and job position as control variables.

\subsection{Data analysis strategy}


In this paper, SPSS22 was used to process the data, test the reliability of the questionnaire and perform basic descriptive statistics, while the process model 4 mediating effect test procedure was used to test the hypotheses. In addition, the Harman one-way test was used for the common method bias problem.

\section{Research results}

\subsection{Common method deviation test.}

Using the Harman one-way test, the results showed that there was essentially no common method bias.

\subsection{Descriptive statistics and correlation analysis}

Correlation analysis of the variables, from Table 1 , it can be seen that psychological contract breach is positively correlated with job insecurity, positively correlated with surface performance, and not correlated with deep performance, job insecurity is significantly positively correlated with surface performance and negatively correlated with deep performance, hypothesis 1, hypothesis 2 , hypothesis $3 \mathrm{a}$, and hypothesis $3 \mathrm{~b}$ were verified.

Table 1: Means, standard deviations, reliability coefficients and correlations of the study variables

\begin{tabular}{|c|c|c|c|c|c|c|c|c|c|c|c|c|c|c|c|}
\hline $\begin{array}{l}\text { Variables } \\
1 .\end{array}$ & M & SD & $\begin{array}{l}1 \\
1.00\end{array}$ & 2 & 3 & 4 & 5 & 6 & 7 & 8 & 9 & 10 & 11 & 12 & 13 \\
\hline $\begin{array}{l}\text { Psychologi } \\
\text { cal } \\
\text { contract } \\
\text { breach }\end{array}$ & 3.07 & 0.62 & & -0.88 & & & & & & & & & & & \\
\hline $\begin{array}{l}\text { 2. Job } \\
\text { insecurity }\end{array}$ & 2.93 & 0.84 & $.50^{* *}$ & 1.00 & -0.72 & & & & & & & & & & \\
\hline 3 . & & & $.26^{* *}$ & $.47 * *$ & & & & & & & & & & & \\
\hline $\begin{array}{l}\text { Neuroticis } \\
\mathrm{m}\end{array}$ & 3.49 & 1.03 & & & 1.00 & -0.79 & & & & & & & & & \\
\hline $\begin{array}{l}\text { 4. Due } \\
\text { diligence }\end{array}$ & 4.52 & 0.86 & -.046 & $-.15^{*}$ & $-.14 *$ & 1.00 & -0.7 & & & & & & & & \\
\hline 5. & & & -10 & $-.12 *$ & & & 1.00 & & & & & & & & \\
\hline $\begin{array}{l}\text { Pleasantne } \\
\text { ss }\end{array}$ & 4.44 & 0.90 & & & -0.12 & $.42 * *$ & & -0.73 & & & & & & & \\
\hline $\begin{array}{l}6 . \\
\text { Openness }\end{array}$ & 3.89 & 1.04 & .061 & -.065 & -0.01 & $.50 * *$ & $\begin{array}{l}.25^{*} \\
*\end{array}$ & 1.00 & -0.85 & & & & & & \\
\hline 7. & & & $-.21^{* *}$ & $-.20 * *$ & & & $.23^{*}$ & & 1.00 & & & & & & \\
\hline $\begin{array}{l}\text { Extroversi } \\
\text { on }\end{array}$ & 3.70 & 1.03 & & & $-.34 * *$ & $.21 * *$ & $*$ & $.22 * *$ & & -0.74 & & & & & \\
\hline 8. Surfa & & & $.37^{* *}$ & $.30 * *$ & & & -.08 & & $-.20^{*}$ & 1.00 & & & & & \\
\hline $\begin{array}{l}\text { ce layer } \\
9 . \quad \text { perfo } \\
\text { rm }\end{array}$ & 3.10 & 0.71 & & & $.38 * *$ & 0.02 & & 0.07 & & & -0.76 & & & & \\
\hline $\begin{array}{l}\text { 9. Deep } \\
\text { performan } \\
\text { ce }\end{array}$ & 3.75 & 0.60 & -.03 & $-.14 *$ & 0.11 & $.52 * *$ & $\begin{array}{l}.49 * \\
*\end{array}$ & $.41 * *$ & $.19 * *$ & -.02 & 1.00 & -0.81 & & & \\
\hline 10. Gender & 1.17 & 0.38 & .00 & $.16^{* *}$ & 0.08 & 0.03 & -.00 & $0.04^{-}$ & -.07 & -.02 & .00 & .00 & & & \\
\hline 11. Age & 2.32 & 0.59 & -.08 & .00 & $-.13^{*}$ & 0.10 & .06 & $0.01^{-}$ & .034 & $-.20 * *$ & -.011 & -10 & & & \\
\hline 12. Jobs & 1.49 & 0.50 & $-.12^{*}$ & $-.16^{* *}$ & $-.13 *$ & $.17 * *$ & .11 & 0.10 & $.12 *$ & $-.15^{*}$ & .06 & $-.14 *$ & $.31 * *$ & & \\
\hline $\begin{array}{l}\text { 13.Educati } \\
\text { on level }\end{array}$ & 3.91 & 0.52 & -.01 & .01 & 0.06 & 0.08 & -.081 & 0.00 & -.03 & .041 & $\begin{array}{l}-.19 * \\
*\end{array}$ & $.14^{*}$ & .003 & -.074 & \\
\hline $\begin{array}{l}14 \text { Years } \\
\text { of work }\end{array}$ & 3.28 & 0.84 & -.11 & .026 & $0.10^{-}$ & 0.07 & .011 & $0.02^{-}$ & .06 & $-.19 * *$ & -.037 & -.12 & $.66^{* *}$ & $.34 * *$ & -.06 \\
\hline
\end{tabular}

Note: $\mathrm{N}=280$, gender: $1=$ male, $2=$ female, internal consistency coefficients for each variable in this study are marked on the diagonal, $* \mathrm{p}<0.05, * * \mathrm{p}<0.01$

\subsection{Intermediary role test}

Mediation tests using process model4 found that psychological contract breach positively predicted job insecurity and shallow performance, and job insecurity positively predicted shallow performance, controlling for job type, education, years of experience, gender, and age. Psychological contract breach was not a significant positive predictor of deep performance, and job insecurity negatively predicted deep performance.

Bootstrap sampling 5000 times showed the indirect effect was significant.
The direct effect from psychological contract breach to deep performance was 0.05 , with a confidence interval of $[-0.08,0.18]$ containing 0 , indicating that the direct effect was not significant. The indirect effect was -0.07 with a confidence interval of $[-0.16,-0.01]$, which did not contain 0 . The indirect effect was significant. Thus job insecurity plays a fully mediating role between psychological contract breach and deep performance, and hypothesis $4 b$ is tested.

\subsection{Intermediary role test with regulation}

Controlling for job position, education, years of 
experience, gender, and age, the psychological contract violation in equation 1 significantly and positively predicted job insecurity, the main effect of job insecurity on shallow performance in equation 2 was not significant, and the interaction effect of job insecurity and neuroticism was significant. The direct effect of psychological contract breach to shallow performance was .29, with a confidence interval of $[.16, .43]$. The mediating effects between psychological contract breach and superficial performance at different neuroticism levels are shown.

Table 2Mediating effects between psychological contract breach and superficial performance at different neuroticism levels

\begin{tabular}{ccccc}
\hline Neuroticism level & Intermediary Effect Value & Boot Standard Error & Bootstrap lower limit & Bootstrap up limit \\
\hline M-SD & -0.04 & 0.05 & -0.16 & 0.06 \\
M & 0.03 & 0.04 & -0.05 & 0.12 \\
M+SD & 0.10 & 0.05 & 0.01 & 0.21 \\
\hline
\end{tabular}

Index value of 0.07 , confidence interval of $[.01, .13]$, excluding 0 , with moderated mediation significant.

To reveal the specific regulatory role of neuroticism, a simple slope test was performed. It was found (see Figure 2) that job insecurity was a higher predictor of shallow performance in employees with high neuroticism $(B=0.25$,
$\mathrm{SE}=0.06, \mathrm{~T}=3.83, \mathrm{p}=0.0002)$ than in employees with low neuroticism traits $(\mathrm{B}=0.05, \mathrm{SE}=0.06, \mathrm{~T}=0.78, \mathrm{p}=0.43)$. This suggests that after developing job insecurity, highly neurotic individuals are more likely to produce shallow performances.

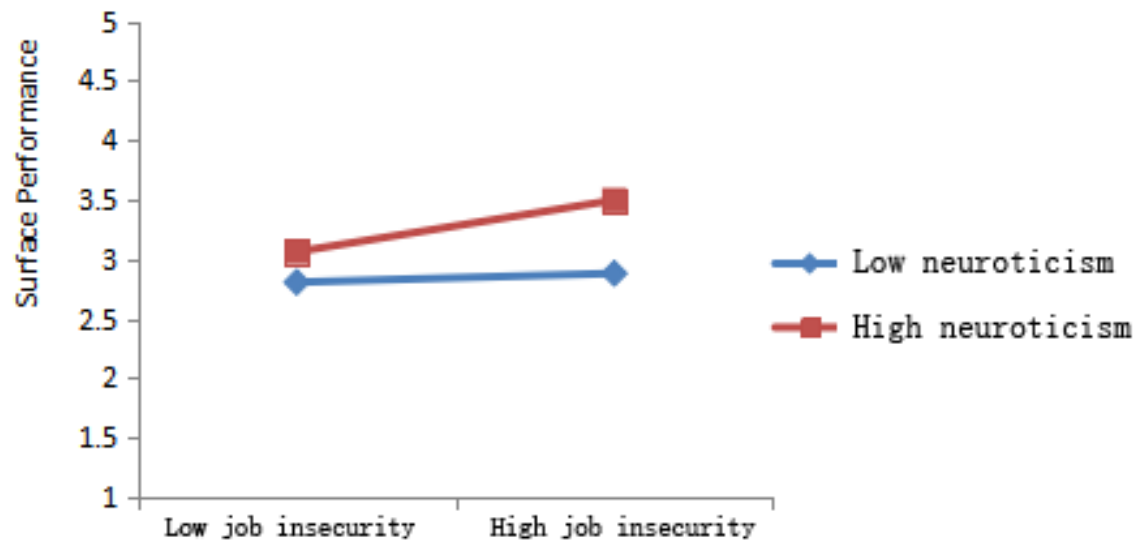

Figure 2: Moderating role of neuroticism between job insecurity and superficial performance

In summary, the mediation model of this study is shown in Figure 3

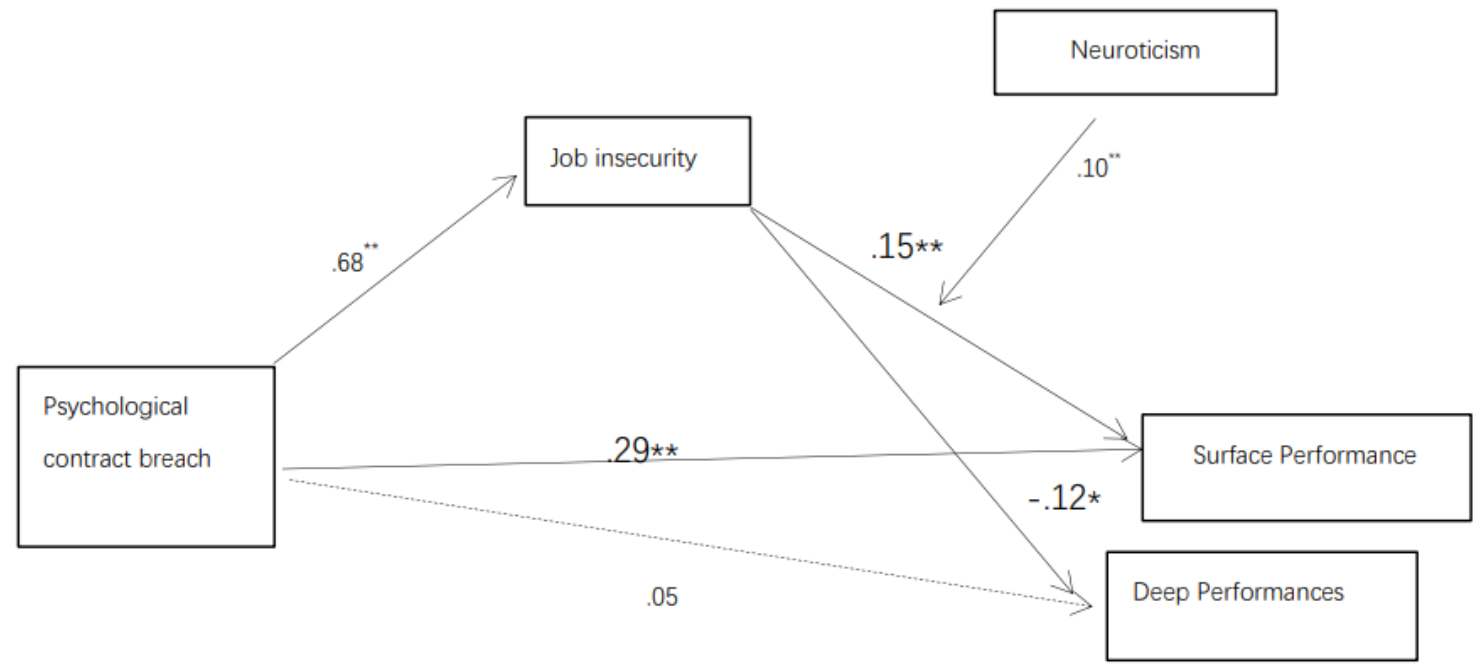

Figure 3: Intermediary model

Note: Figures shown are standardized path coefficients, ${ }^{*} \mathrm{p}<0.05 ; * * \mathrm{P}<0.01, * * * \mathrm{p}<0.001$, the dashed line in the figure represents a non-significant path coefficient, the solid line represents a significant path coefficient. 


\section{Conclusion}

\subsection{Conclusion of the study}

(1) This study found that in the manufacturing industry, employees exhibit certain emotional labor when faced with negative emotional events.

(2) Job insecurity fully mediates the relationship between psychological contract breach and deep performance, i.e., the production of psychological contract breach does not directly but fully affect deep performance through job insecurity.

(3) Job insecurity partially mediates the relationship between psychological contract breach and surface performance, referring to the fact that psychological contract breach can affect surface performance by affecting employees' insecurity, and can also directly affect surface performance.

(4) Neuroticism moderates the relationship between job insecurity and shallow performance, i.e., the higher the neuroticism, the more susceptible people are to job insecurity and the more likely they are to exhibit shallow performance.

\section{Reference.}

1. Grandey, A. (2000). Emotional regulation in the workplace: A new way to conceptualize emotional labor. Journal of Occupational Health Psychology, 5(1), 95-110.

2. Probst \& Lawler(2006).Cultural Values as Moderators of Employee Reactions to Job Insecurity: The Role of Individualism and Collectivism: International Review of Applied Psychology volume 55,Issue 2

3. Klandermans, B., van Vuuren, T., \& Jacobson, D. ( 1991). Employees and job insecurity. In J.Hartley,D.Jacobson, B.Klandermans, \& T.van Vuuren ( Eds.), Job insecurity: Coping with jobs at risk (pp. 40-64). London, England: Sage.

4. Cullen, M. J., \& Sackett, P. R. (2003). Personality and counterproductive workplace behavior. In M. R. Barrick \& A. M. Ryan (Eds.), Personality and work (pp. 150-182). San Francisco: Jossey-Bass

5. Sackett, P. R., \& DeVore, C. J. (2001). Counterproductive behaviors at work. In N. Anderson, D. S. Ones, H. K. Sinangil, \& C. Viswesvaran(Eds.), Handbook of industrial, work, and organizational psychology(Vol. 1, pp. 145-164). London: Sage.

6. Rousseau, D. M. (1989). Psychological and implied contracts in organizations. Employee Responsibilities and Rights Journal, 2, 131-139.

7. Rousseau, D. M. (1995). Psychological contracts in organizations: Understand written and unwritten agreements. Thousand Oaks, CA: Sage.116

8. Robinson, S. L., \& Rousseau, D. M. (1994). Violating the psychological contract: Not the exception but the norm. Journal of Organizational Behavior, 15, 245259.

9. Argyris ,C. (1961) . Understanding Organizational Behavior. Oxford University Press,Oxford,156-157

10. Robinson, S. L. and Bennett, R. J. (1993). 'The four P's of destruction: A multi-dimensional scaling study of deviance in the workplace'. Presented at the Academy of Management Meeting, Atlanta.

11. Burke, R. J. (1998). Job insecurity in recent business school graduates: Antecedents nd consequences. International Journal of Stress Management, 5, 113-119.

12. Morrison, E.W. and Robinson, S.L. (1997). When Employees Feel Betrayed: A Model of How Psychological Contract Violation Develops. Academy of Management Review, 22, 226-256

13. Hochschild, A. R. (1983). The managed heart: Commercialization of human feeling $[\mathrm{M}]$. Berkeley: University of California Press

14. Glomb TM \& Tews MJ.(2004). Emotional labor: a conceptualization and scale development. J Vocational Behav,2004,6(1):1-23

15. Gross, (1998). Antecedent- and Response-focused Emotion Regulation: Divergent Consequences for Experience ,Experience, and Physiology", Journal of Personality Social Psychology, 74(1): 224-237.

16. Sverke M, Hellgren J. (2002). The nature of job insecurity: understanding employment uncertainty on the brink of a new millennium. Applied psychology: an international review, 51(1): 23-42

17. Hellgren J, Sverke M, Isaksson K. (1999). A towdimensional approach to job insecurity : eonsequencesfor employee atti-tudes and wellbeing . European Journal of Work and Organizational Psychology, 8(2): 179-195

18. Klandermans, B., van Vuuren, T., \& Jacobson, D. (1991). Employees and job insecurity. In J.Hartley,D.Jacobson, B.Klandermans, \& T.van Vuuren ( Eds.), Job insecurity: Coping with jobs at risk (pp. 40-64). London, England: Sage.

19. De WH. (1999). Job insecurity and psychological well-being: Review of the literature and exploration of some unresolved issues. European Journal of Work and Organizational Psychology, 8(2): 155-177

20. Morris, A. and Feldman, D. (1996) . The dimensions, antecedents, and consequences of emotional labour. Academy of Manage- ment Review 21, 986-1010 